\title{
Size-dependent aerosol deposition velocities during BEARPEX'07
}

\author{
R. J. Vong ${ }^{1}$, I. J. Vong ${ }^{1}$, D. Vickers ${ }^{1}$, and D. S. Covert ${ }^{2}$ \\ ${ }^{1}$ College of Oceanic and Atmospheric Sciences, Oregon State University, Corvallis, OR 97331, USA \\ ${ }^{2}$ Joint Institute for the Study of Atmospheres and Oceans, University of Washington, Seattle, WA 98195, USA
}

Received: 17 December 2009 - Published in Atmos. Chem. Phys. Discuss.: 16 February 2010

Revised: 9 June 2010 - Accepted: 18 June 2010 - Published: 30 June 2010

\begin{abstract}
Aerosol concentrations and 3-D winds were measured from 9 to 25 September 2007, above a pine forest in California. The measurements were combined using the eddy covariance (EC) technique to determine aerosol eddy fluxes as a function of particle diameter within the accumulation mode size range $\left(0.25 \mu \mathrm{m} \leq D_{p} \leq 1 \mu \mathrm{m}\right.$ here $)$. Measured heat and water vapor fluxes were utilized to correct the aerosol eddy fluxes for aerosol hygroscopic growth. The hygroscopic growth correction was necessary despite the low $\mathrm{RH}$ and relatively hygrophobic nature of the particles. Uncertainties associated with particle counting also were evaluated from the data. Aerosol deposition velocities $\left(V_{d}=\mathrm{EC}\right.$ turbulent flux/mean particle concentration) during daytime were shown to vary from -0.2 to $-1.0 \mathrm{~cm} \mathrm{~s}^{-1}$; the magnitude of particle $V_{d}$ increases with friction velocity and particle diameter.
\end{abstract}

\section{Introduction}

Removal of aerosol particles to vegetation by atmospheric turbulence is the focus of this experiment that addresses factors which control the magnitude of aerosol flux and key uncertainties in its measurement using the eddy correlation technique. These factors relate to aerosol microphysics, aerosol chemical composition, and boundary layer dynamics.

The concentration and chemical composition of atmospheric, accumulation mode $\left(0.1 \mu \mathrm{m}<D_{p}<2.0 \mu \mathrm{m}\right)$ aerosol are important influences on the Earth's climate, air quality, clouds, and precipitation (Charlson et al., 1992; Charlson et al., 1987). The composition, concentration, and spatial distribution of aerosol are controlled by emission, transport and

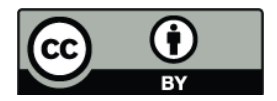

Correspondence to: R. J. Vong

(vong@coas.oregonstate.edu) mixing, chemical and physical processing, and deposition. Aerosol removal via clouds and precipitation is known as wet deposition while removal by cloud-free, turbulence related processes (including impaction, interception and diffusion) and gravitational settling are termed dry deposition.

Dry deposition can contribute a substantial fraction (up to one-half) of the total chemical mass in atmospheric deposition (Erisman et al., 1997; Hicks et al., 1991) and can result in potentially significant impacts on terrestrial and aquatic ecosystems. However, rates and mechanisms for the removal of accumulation mode particles by turbulence are not well known nor is the dependence of particle deposition velocity $\left(V_{d}\right)$ on diameter (Pryor et al., 2008; Seinfeld and Pandis, 1998). This study particularly addresses particle fluxes to a second growth forest which is typical of those that have been planted across the western United States.

\section{Methods}

\subsection{Site}

Aerosol concentrations and winds were measured from 9 to 25 September 2007, above a pine forest owned by Sierra Pacific Industries, adjacent to the University of California at Berkeley's Blodgett Forest Research Station as part of the Biosphere Effects on Aerosols and Photochemistry Experiment (BEARPEX). The site is located $75 \mathrm{~km}$ NE of Sacramento, $\mathrm{CA}\left(38^{\circ} 59^{\prime} \mathrm{N}, 120^{\circ} 58^{\prime} \mathrm{W}\right)$ at $1315 \mathrm{~m}$ elevation on the western slope of the Sierra Nevada mountains. The area was planted with Pinus ponderosa in 1990 with a few other species present; average canopy height is $7.9 \mathrm{~m}$. The understory is composed of manzanita and mountain whitehorn shrubs up to $2 \mathrm{~m}$ in height. The leaf area index for the full canopy was $5.1 \mathrm{~m}^{2} / \mathrm{m}^{2}$. A detailed description of the site is provided by Goldstein et al. (2000). The daytime fetch is excellent in that the upwind (winds from the SE to W) canopy

Published by Copernicus Publications on behalf of the European Geosciences Union. 
is even aged and uniform over a distance of $2 \mathrm{~km}$ and the terrain is gently sloped $\left(2^{\circ}\right)$. The night time fetch (winds from the $\mathrm{E}$ and $\mathrm{N}$ ) is not as good because of uneven upwind terrain and advection of emissions from the site's electrical generator (located $\sim 125 \mathrm{~m}$ to the $\mathrm{N}$ ).

\subsection{Instrumentation}

Aerosol concentrations as a function of particle diameter were measured by light scattering techniques. The FAST aerosol spectrometer (Flux Aerosol Spectrometer Technique, Droplet Measurement Technologies, DMT Boulder CO) provided particle concentration at $10 \mathrm{~Hz}$ as a function of size for the eddy covariance (EC) fluxes while two identical optical particle counters (OPC, WELAS 1200, Palas, Karlsruhe, Germany) measured the aerosol size spectra and hygroscopic growth at $5 \mathrm{~min}$. resolution. The FAST and OPCs provided detailed resolution of the aerosol size spectrum for much of the accumulation mode size range $\left(0.25 \mu \mathrm{m} \leq D_{p} \leq 1.0 \mu \mathrm{m}\right.$ here).

The FAST illuminates the aspirated aerosol particles with a $680 \mathrm{~nm}$ laser and detects the scattered light $\left(5^{\circ}\right.$ to $14^{\circ}$ forward collection angle) (Vong et al., 2004). The FAST was size-calibrated using PSL particles and its counting efficiency was determined as a function of $D_{p}$ by comparison to a second instrument (UHSAS, DMT Boulder CO) in the laboratory and to the OPCs in the field. The FAST particularly undercounted the smaller particles compared to the UHSAS and OPCs before correction; this counting correction was a factor of 3.3 at $D_{p}=0.30 \mu \mathrm{m}$ and 1.7 at $D_{p}=0.49 \mu \mathrm{m}$. The FAST was operated continuously during daytime and some nights.

The two WELAS white-light OPCs were operated regularly but not continuously each day to quantify aerosol hygroscopic growth (Hegg et al., 2006, 2007, 2008) during the morning, afternoon and early evening hours. Water vapor was added to and removed from the sample air upstream of the two OPCs to achieve relative humidities (RH) that bracketed the ambient $\mathrm{RH}$ for that time period in order to determine the hygroscopic growth parameter $(\gamma)$ relevant for the FAST measurement. The OPCs were located inside a sampling van at the base of the tower and drew air at $121 \mathrm{~min}^{-1}$ through a common $1 / 2 \mathrm{~cm}$ dia. conductive polyethylene tube from the $18.8 \mathrm{~m}$ a.g.l. tower level near the EC instrumentation. The OPCs were size calibrated with PSL particles of 250 to $900 \mathrm{~nm}$. Their counting efficiency was determined by comparison to condensation particle counters (Model 3010, TSI, St. Paul MN) using PSL selected by a differential mobility analyzer (Model 3071, TSI). Particle losses for the OPC inlet and sampling line were less than $0.7 \%$ for $\left(0.2 \mu \mathrm{m} \leq D_{p} \leq 1.0 \mu \mathrm{m}\right)$ including gravitational, diffusional, and inertial mechanisms for a reasonable particle density of $1.5 \mathrm{~g} \mathrm{~cm}^{-3}$ (Baron and Willeke, 2005).

Water vapor was measured in situ at $10 \mathrm{~Hz}$ by ultraviolet absorption (Model KH-20 Campbell Scientific, Logan UT), three dimensional winds and virtual temperature at $10 \mathrm{~Hz}$ using an ultrasonic anemometer (Model SWS-211-3K Appl. Tech. Inc., Boulder CO), and temperature and RH (Model HMP-45C Campbell Scientific, Logan UT) gradients were measured at $30 \mathrm{~min}$ intervals (at $18.8 \mathrm{~m} / 7.3 \mathrm{~m}$ a.g.1.).

The EC technique combined aerosol concentrations from the FAST, water vapor density from the KH-20, and 3-D winds from the sonic anemometer as calculated covariances; all of these measurements were performed from the top of a scaffolding tower at $18.8 \mathrm{ma}$ a.g.l. The EC instruments were mounted on a boom that extended $2 \mathrm{~m}$ upwind of the SW tower corner in order to minimize flow distortion from the scaffolding. The instruments were periodically oriented (generally 2 to 3 times per day) into the prevailing wind direction by rotating the boom. When the boom was rotated, inlet nozzles of varying diameter matched the FAST aspiration velocity to ambient wind speed (usually within $\pm 25 \%$ ) to achieve near isokinetic sampling. Inlet losses were calculated as $0.3 \%$ for a $\pm 25 \%$ non-isokinetic match of velocities for $D_{p}=1 \mu \mathrm{m}$, wind speed $=2 \mathrm{~m} \mathrm{~s}^{-1}$ and $T=25^{\circ} \mathrm{C}$ (Baron and Willeke, 2005).

\subsection{Data processing for aerosol EC fluxes}

The eddy covariance (EC) fluxes for the FAST were determined after combining the particle concentrations from its twenty aerosol size intervals into six broader size intervals to obtain more total counts for each diameter interval within each $30 \mathrm{~min}$. flux period. These six aerosol sizes covered the range $0.25 \mu \mathrm{m} \leq D_{p} \leq 1.0 \mu \mathrm{m}$. Thus, aerosol concentrations and fluxes were determined separately from the FAST for the diameters listed in Table 1.

In a $0.1 \mathrm{sec}$. sampling interval, the FAST typically counted 1 to 10 particles in the larger diameter $\left(D_{p} \geq 0.5 \mu \mathrm{m}\right)$ intervals but 5 to 40 particles for the smaller intervals (e.g., $0.3 \mu \mathrm{m}$ ). For any 30 min eddy flux during BEARPEX, the total particle counts in any diameter interval varied from $\sim 10^{4}$ to $2 \times 10^{5}$.

Periods with at least 28 (of 30 ) min of valid data were retained for further analysis. Data were deemed valid after screening for periods with signal dropouts, activity on the tower, sonic anemometer or hygrometer spikes during rain, boom rotation, and poor upwind fetch. The screening identified periods with unusual data variance to screen out periods with non-stationarity. To avoid these problems as well as the result of applying standard micrometeorological screening of eddy flux data (Vickers and Mahrt, 1997, 2003), the data set was reduced to its most ideal periods: 316 total 30min periods with valid aerosol eddy fluxes (most were daytime hours) with 67 of these periods also having aerosol hygroscopic growth measurements (twice each day).

After the above data screening steps, tilt and coordinate system rotations were investigated (Lee et al., 2004). The derived rotation ("attack") angle ( $2^{\circ}$ mean) matched the slope of the upwind terrain such that vertical fluxes were both "surface normal" and streamline normal. This attack angle 
Table 1. FAST sensing diameter: ranges and mid-points.

\begin{tabular}{lll}
\hline FAST channel & $D_{p}$ interval, $\mu \mathrm{m}$ & Mid-point $D_{p}, \mu \mathrm{m}$ \\
\hline A & 0.246 to 0.280 & 0.26 \\
B & 0.28 to 0.31 & 0.30 \\
C & 0.31 to 0.34 & 0.33 \\
D & 0.34 to 0.44 & 0.40 \\
E & 0.44 to 0.54 & 0.49 \\
F & 0.54 to 1.01 & 0.78 \\
\hline
\end{tabular}

derived from the daytime BEARPEX data resulted in similar EC fluxes whether rotations were derived from data for each $30 \mathrm{~min}$. flux period or alternatively based on mean "attack angle" as a function of wind direction (Kowalski et al., 1997). These different rotation criteria also produced similar values for friction velocity $\left(u^{*}\right)$ indicating that the fluxes are not sensitive to the rotation criteria at this site.

The eddy covariance heat, water vapor, and momentum fluxes that are reported here showed good agreement with those measured independently by Univ. of California collaborators for the same time periods (regression slopes were 0.96 to $1.1 ; r^{2}=0.77$ to 0.92 ) despite the fact that their fluxes were measured from a second tower that was located $12 \mathrm{~m}$ away (cross wind) and at a lower height (13 m a.g.l. for U.C. vs. $18.8 \mathrm{~m}$ here). This type of consistency between fluxes measured at different heights and cross wind locations suggests that these EC measurements are representative of the upwind fetch.

\section{Results}

\subsection{General}

The winds were predictable with upslope winds ( $\mathrm{S}$ to $\mathrm{W}$ ) over good fetch from late morning until sundown each day but down slope winds ( $\mathrm{N}$ to $\mathrm{E}$ ) at night and early morning. Concentrations were quite low except for a few periods when forest fires elevated particle and gas concentrations (these fire periods were removed by the screening procedures; see Sect. 2.3); Table 2 provides mean aerosol number concentrations and deposition velocities for BEARPEX 2007. The ambient relative humidity was in the range $15 \%<\mathrm{RH}<40 \%$ during most daytime periods. Very little to no generator influence on accumulation mode particle concentration was detected during the steady upslope winds that characterized daytime periods based on subsequent measurements of ultrafine particle concentrations.

\subsection{Eddy covariance fluxes}

Figure 1 presents the measured diurnal variation of aerosol deposition velocity $\left(V_{d}=\mathrm{EC}\right.$ turbulent flux / mean particle
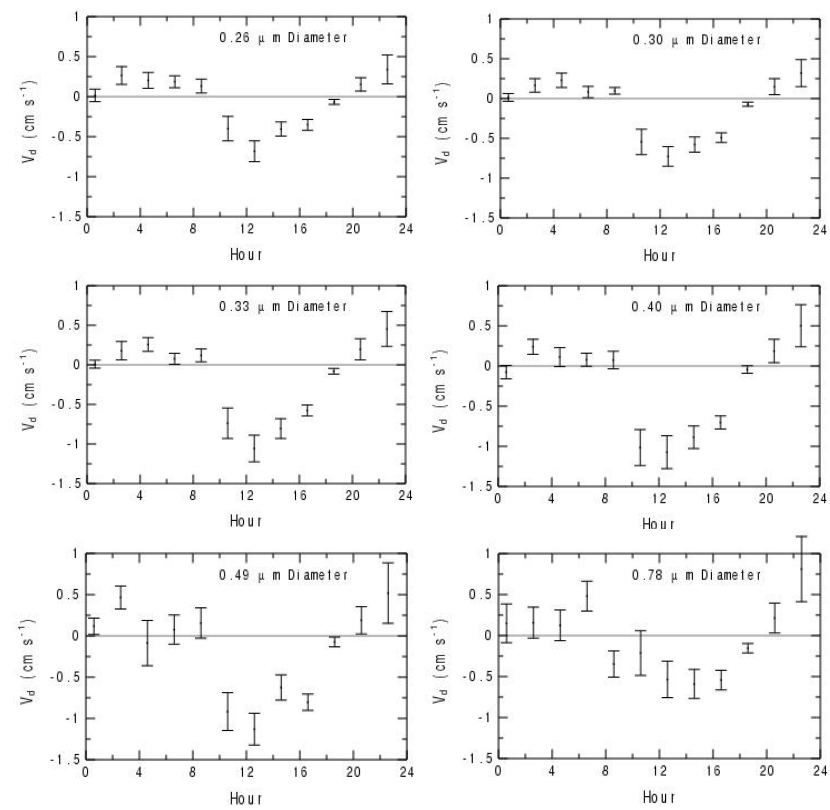

Fig. 1. Diurnal variation of aerosol deposition velocity for six particle diameters as measured during BEARPEX 2007 (negative $V_{d}$ is downward). No corrections have been applied to these data. Bars indicate \pm one data standard error for values recorded during that two hour period. Times are given as PST.

concentration) during BEARPEX. In this paper we use the convention that negative $V_{d}$ and fluxes are downward. Deposition velocities are presented to characterize the aerosol turbulent fluxes to remove both the dependence of flux on concentration and the counting efficiency correction. Aerosol fluxes and the magnitude of the deposition velocities were larger during mid-afternoon than mornings or evenings. Analysis of daytime sonic anemometer data indicates that the turbulence at the measurement height is fully developed (Stull, 1988; Foken et al., 2004) in that the expected relationship exists among vertical and horizontal turbulent wind components $\left(\sigma_{w}=1.33 u^{*}\right.$ with $r^{2}=0.93$, where $\sigma_{w}$ is the standard deviation of the vertical wind component and $u^{*}$ is the friction velocity, both over $30 \mathrm{~min}$.).

\subsection{Counting uncertainties}

The uncertainty for single 30-min. EC aerosol fluxes due to the discrete nature of aerosol "counting" was calculated as $\sigma_{w} / \sqrt{ } \mathrm{N}$ (Fairall, 1984; Nemitz et al., 2002; Vong et al., 2004) where $\mathrm{N}$ is the number of particles counted in $30 \mathrm{~min}$ for a particular particle size. Counting uncertainties, in terms of the particle deposition velocity, were \pm 0.14 to $0.21 \mathrm{~cm} \mathrm{~s}^{-1}$ for the smaller particles $\left(0.25 \mu \mathrm{m} \leq D_{p} \leq 0.44 \mu \mathrm{m}\right)$ but were $\pm 0.55 \mathrm{~cm} \mathrm{~s}^{-1}$ for the larger particles $\left(0.5 \mu \mathrm{m} \leq D_{p} \leq 1.0 \mu \mathrm{m}\right)$ for single 30 -min. EC aerosol flux periods. These counting uncertainties are acceptable for the smaller $\left(D_{p}<0.5 \mu \mathrm{m}\right)$ particles but are large 
Table 2. Mean daytime (10 a.m.-3 p.m.) aerosol properties during BEARPEX 2007.

\begin{tabular}{lllll}
\hline$D_{p} \mu \mathrm{m}$ & Concentration $\mathrm{cm}^{-3}$ & Mean deposition velocity $V_{d} \mathrm{~cm} \mathrm{~s}^{-1}$ & Regression of $V_{d}$ on binned $U^{*}$ & Regression $r^{2}$ \\
\hline 0.26 & 59 & -0.18 & $-V_{d}=0.29\left(U^{*}\right)^{0.83}$ & 0.44 \\
0.30 & 85 & -0.29 & $-V_{d}=0.42\left(U^{*}\right)^{0.72}$ & 0.21 \\
0.33 & 22 & -0.46 & $-V_{d}=0.99\left(U^{*}\right)^{1.11}$ & 0.71 \\
0.40 & 10 & -0.63 & $-V_{d}=1.63\left(U^{*}\right)^{1.42}$ & 0.89 \\
0.49 & 2 & -0.61 & N.A. & dna \\
0.78 & 1 & -0.38 & N.A. & dna \\
\hline
\end{tabular}

N.A. = not appropriate due to higher counting errors.

enough to substantially reduce confidence in the results for the larger $\left(D_{p} \geq 0.5 \mu \mathrm{m}\right)$ particles.

\subsection{Spectra and co-spectra}

Figure 2 presents BEARPEX aerosol frequency spectra from the FAST spectrometer, spectra of vertical velocity, water vapor density, and sonic temperature (which is a close approximation to $T_{v}$ ), their co-spectra, and the [-5/3] spectral slope that would be expected for an instrument with an ideal response. While vertical velocity, water vapor, and virtual temperature $\left(T_{v}\right)$ behave as expected, aerosol concentration for all six particle diameters does not. The flattening of particle concentration variance in the spectrum suggests that noise is present and that the FAST did not fully resolve aerosol concentration at the higher frequencies.

There is no appreciable difference between the particle spectra for six different diameters in that they begin to flatten out at frequencies in the range 0.05 to $0.2 \mathrm{~Hz}$ (Fig. 2, top panel). These spectra for heat, water vapor and vertical wind speed follow the [-5/3] theoretical slope suggesting that these quantities are well determined out to $5 \mathrm{~Hz}$ (Fig. 2, middle panel). The effect of averaging time on the computation of EC fluxes was found to be minimal in that 10-min. or 30 -min. mean removal made only $1-2 \%$ difference in the 30 min fluxes.

The bottom panel in Fig. 2 presents cospectra as the cumulative, normalized, covariance for heat, water vapor, particles ( $D_{p}=0.3 \mu \mathrm{m}$ is displayed; other particle diameters behave similarly), and momentum. The particle flux occurs over the same frequency ranges as heat, moisture, and momentum fluxes for frequencies less than $0.5 \mathrm{~Hz}$. The heat and vapor turbulent fluxes have a 12 to $16 \%$ contribution to their total fluxes above $0.2 \mathrm{~Hz}$ while the particle fluxes have a similar contribution (15.6\% of the measured covariance for $0.3 \mu \mathrm{m}$ $D_{p}$ particles). Above $0.5 \mathrm{~Hz}$ the particle cospectrum falls to near zero whereas the heat and water vapor fluxes still contribute $6-9 \%$ of the total covariance.
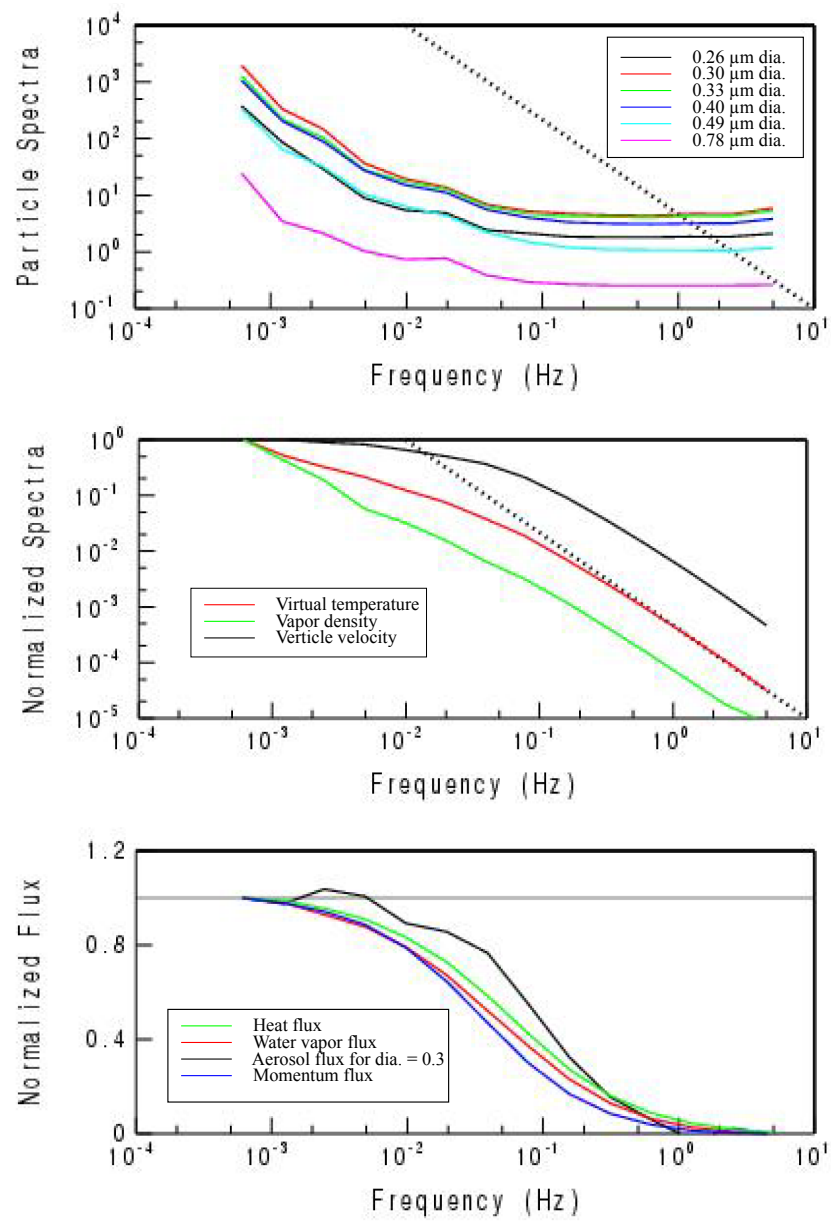

Fig. 2. Spectra and co-spectra for the indicated variables from 70 daytime $30 \mathrm{~min}$ periods (for the $25 \%$ of periods with the highest aerosol concentrations during BEARPEX). The variances and covariances (and their normalized values) that are presented on the Yaxes were calculated using the multiresolution decomposition methods described by Howell and Mahrt (1997) and Vickers and Mahrt (2003). 
For an assumption of cospectral similarity (Eugster and Senn, 1995) for water vapor, heat and particles, a comparison of the cospectra in the bottom panel of Figure 2 suggests that the FAST missed 6-9\% of the aerosol EC flux at the higher frequencies. This contrasts to estimates of flux loss from the particle spectrum which suggest greater losses in the range of 16 to $50 \%$ due to the signal appearing to become increasingly "white noise" at frequencies in the range 0.05 to $0.2 \mathrm{~Hz}$ and higher. The smaller error estimate (6-9\%) is based on the amount of vapor and heat flux above $0.5 \mathrm{~Hz}$ (where the particle covariance becomes small) whereas the larger estimates from the spectrum (16-50\%) assume that the FAST lost all flux above 0.2 and $0.05 \mathrm{~Hz}$, respectively. Since there is covariance captured between vertical wind and the FAST particle concentrations above this range ( 0.05 to $0.2 \mathrm{~Hz}$ ), the FAST cannot be completely white noise at these frequencies because random variables do not display covariance. Thus, the estimates of lost flux due to high frequency noise in the FAST are taken from the cospectral estimates rather than from the particle spectrum in Fig. 2.

Most of the aerosol flux is transported over time scales of 2 to 200 seconds while the heat, vapor and momentum fluxes, according to the cospectra, are transported by slightly larger eddies with time scales of 2 to $500 \mathrm{~s}$. Although it is clear that the FAST is not an ideal EC scalar sensor based on the co-spectra, it did capture covariance in the same frequency ranges that dominated the other turbulent fluxes. After applying a low-pass noise filter with a cutoff frequency of $0.5 \mathrm{~Hz}$ (half power of the filter) the spectra follow the $[-5 / 3]$ slope in the inertial sub-range. The scale dependence of the flux is nearly the same for the unfiltered and filtered time series, indicating that the high-frequency noise does not contribute significantly to the eddy flux.

The particle fluxes would be attenuated at the higher frequencies (Moore, 1986) due to the 0.9 meter lateral separation of the FAST from the sonic anemometer but these corrections are not important here because the aerosol spectrometer does not resolve these frequencies (Fig. 2, top panel) and very little of the observed particle flux occurs at these time scales (Fig. 2, bottom panel).

\subsection{Aerosol hygroscopic growth}

The FAST, by necessity, operates at ambient RH. Since RH can vary rapidly in time due to upward and downward transport of parcels from layers with higher or lower humidity, and because ambient aerosol is hygroscopic in varying degrees, a given aerosol number-size distribution will vary with changing RH and affect the EC fluxes from the FAST. Even if the hygroscopic growth factor is small, the effect on EC fluxes can be large if the slope of the size distribution is steep in the range covered by the FAST. For a typical accumulation mode number-size distribution with a steep negative slope, the FAST will report a larger concentration at a given size increment within a higher RH parcel compared to that mea- sured at a lower RH due to the hygroscopic growth-size shift in the distribution. The converse will occur with lower RH parcels. Thus, a hygroscopic growth measurement and correction is needed for this EC flux measurement. Hygroscopic growth is determined by the chemical composition of the aerosol and does not vary rapidly in time under conditions that are required for flux measurements.

The hygroscopic aerosol growth parameter, $\gamma$, was calculated twice daily from aerosol size spectra measured by OPCs operating at different RH. Equation (1) (Kasten, 1969; Vong et al., 2004; Massling et al., 2005) relates the measured diameters to yield the hygroscopic growth parameter $(\gamma)$ as

$D\left(S_{\text {high }}\right) / D\left(S_{\text {low }}\right)=\left[\left(1-S_{\text {high }}\right) /\left(1-S_{\text {low }}\right)\right]^{-\gamma}$

where: $S$ is saturation ratio $(S=\mathrm{RH} / 100 \%), S_{\text {low }}$ and $S_{\text {high }}$ describe the high and low RH values during OPC scans, $D$ is aerosol optical diameter at the given saturation ratio.

\subsection{Hygroscopic growth correction to aerosol deposition velocity}

A correction to aerosol EC fluxes, in terms of deposition velocity, due to any hygroscopic growth of particles is given as (Vong et al., 2004; Kowalski, 2001; Fairall, 1984):

$\Delta V_{d}=-\beta \gamma \overline{w^{\prime} S^{\prime}} /(1-S)$

All the components of this $V_{d}$ correction were measured during BEAREPX 2007: the slope of the aerosol numbersize distribution $(\beta)$, the hygroscopic growth parameter $(\gamma)$, the saturation ratio, and the saturation ratio flux $\left(\overline{\mathrm{w}^{\prime} \mathrm{S}^{\prime}}\right)$. This approach assumes that updrafts and downdrafts have similar hygroscopic properties. In this presentation $V_{d}, \Delta V_{d}$ and $\widehat{\mathrm{w}^{\prime} \mathrm{S}^{\prime}}$ have the same sign convention as vertical velocity (negative is downwards).

During BEARPEX the hygroscopic growth parameter $(\gamma)$ was measured to be in the range $0<\gamma<0.14$ for $95 \%$ of the measurements based on 258 valid scans with a mean value of $\gamma=0.07$ over the optical size range of 0.3 to $1.0 \mu \mathrm{m}$. There was no difference in measured $\gamma$ with diameter and no trend with time during BEARPEX. Fig. 3 displays the variation in the exponent for Eq. (1) (presented as $-\gamma$ ) and a Gaussian fit for comparison to its frequency distribution.

This small value of $\gamma$ during BEARPEX compares to $\gamma=0.25$ for pure ammonium sulfate aerosol (Vong et al., 2004). Thus, the BEARPEX aerosol were much less hygroscopic than sulfate or other inorganic, combustion-derived particulate chemistry. For humidity changes from low RH ( $\mathrm{RH} \leq 30 \%$ ) to $90 \% \mathrm{RH}$, the typical BEARPEX aerosol grew by a factor of 1.15 in diameter while sulfate particles would grow by a factor of 1.78. These results are consistent with previous measurements of hygroscopic growth of aerosol in the California Sierra Nevada region where Carrico et al. (2005) measured particle growth by factors of 1.11 and 1.29 for two observed modes of the aerosol (for $0.2 \mu \mathrm{m} D_{p}$ at high RH). 


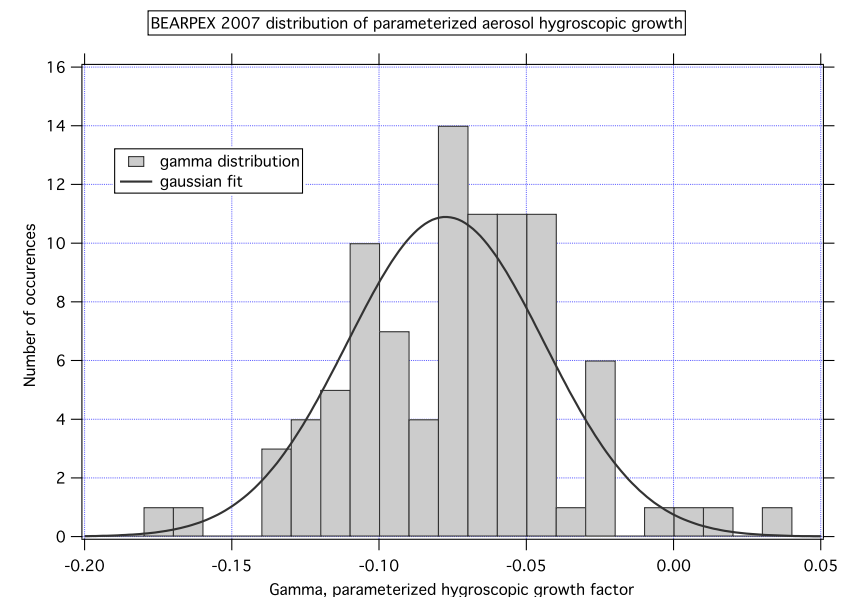

Fig. 3. Measured aerosol hygroscopic growth parameter, plotted as the exponent $(-\gamma)$ in Eq. (1), during BEARPEX 2007. The plot shows frequency of occurrence and a Gaussian fit to the distribution.

The aerosol size distribution during BEARPEX, characterized by the "Junge" (Junge, 1963) slope ( $\beta$ : as defined from $d N / d \log D=c D^{-\beta}$ ) was calculated for every $30 \mathrm{~min}$. flux interval for each FAST diameter interval and shown to be "very steep". $\beta$ decreased with increasing $D_{p}(\beta=10.1,6.1$, and 3.9 for $D_{p}=0.35,0.45$, and $0.55 \mu \mathrm{m}$, respectively). Because of these steep slopes there were high concentrations of smaller particles that could grow into a given FAST diameter interval in higher RH air parcels arriving at the FAST during vertical transport. Similarly, there were few larger particles that could shrink into a given diameter interval when $\mathrm{RH}$ decreased during vertical transport. Figure 4 presents the average aerosol size distribution from the OPCs.

The saturation ratio flux is defined as (Kowalski 2001; Fairall, 1983):

$\overline{w^{\prime} S^{\prime}}=\overline{w^{\prime} q^{\prime}} / q_{\mathrm{sat}}-\overline{w^{\prime} T^{\prime}}\left(S L_{v}\right) /\left(R_{v} T^{2}\right)$

where: $q_{\text {sat }}$ is the saturation specific humidity, $L_{v}$ is the latent heat of vaporization for water, $R_{v}$ is the gas law constant for water, $\overline{w^{\prime} T^{\prime}}$ is the sensible heat flux, and $\overline{w^{\prime} q^{\prime}}$ is the water vapor turbulent flux.

This saturation ratio flux was determined from measured $10 \mathrm{~Hz}$ heat and water vapor EC fluxes according to Eq. (3) and was similar to values observed over grass in Oregon during EFLAT by Vong et al. (2004). The positive values of $\overline{\mathrm{w}^{\prime} \mathrm{S}^{\prime}}$ (upward fluxes) in Fig. 5 were observed at night or early morning while negative values (i.e., downward $\overline{w^{\prime} S^{\prime}}$ ) were observed during the middle of the day.

During the daytime, measured aerosol deposition velocities change by becoming less downward (usually 30minute $\Delta V_{d}=0.1-0.4 \mathrm{~cm} \mathrm{~s}^{-1}$ with maximum $\Delta V_{d}$ of 0.3 $0.9 \mathrm{~cm} \mathrm{~s}^{-1}$, depending on $D_{p} ; \Delta V_{d}$ decreases in magnitude with increasing $D_{p}$ due to $\beta$ ) after a hygroscopic growth correction. This hygroscopic behavior of the particles reflected

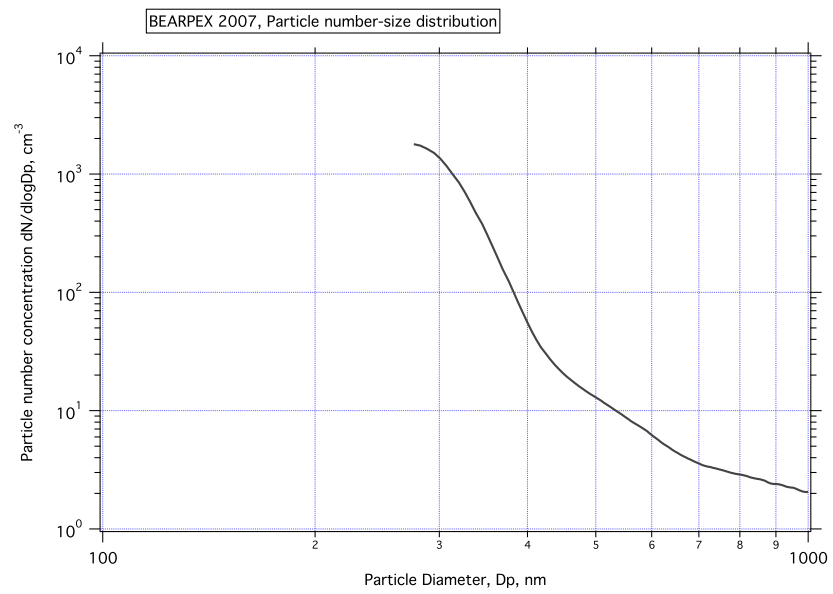

Fig. 4. Mean aerosol size distribution from the OPC during BEARPEX'07.

the fact that RH was 1 to $6 \%$ higher at the top of the tower (at $18.8 \mathrm{~m}$ a.g.l.) than below (at $7.3 \mathrm{~m}$ a.g.l.) during daytime making saturation ratio flux $\overline{\mathrm{w}^{\prime} \mathrm{S}^{\prime}}$ downward (negative). At night or during the early morning periods when RH was 5 to $15 \%$ higher near the ground than at the top of the tower, the measured aerosol deposition velocities change by a smaller amount $\left(\leq 0.1 \mathrm{~cm} \mathrm{~s}^{-1}\right)$ and become more downward after a hygroscopic growth correction. The hygroscopic growth correction during BEARPEX 2007 reduces the magnitude of both upward and downward aerosol eddy fluxes and deposition velocities compared to observed, uncorrected values.

Figure 6 displays the measured and hygroscopic growthcorrected aerosol deposition velocities for six aerosol diameters plotted against friction velocity $\left(u^{*}\right)$ to demonstrate the magnitude of the correction. In these plots, the uncertainties represent \pm one data standard error of the measured values among the 316, 30-min observations that are included for each diameter (negative $V_{d}$ is downward).

\subsection{WPL corrections}

Webb-Pearman-Leuning (WPL) corrections (Webb et al., 1980) were performed to determine how the aerosol deposition velocity was affected by vertical variations in air density (associated with $T$ and RH gradients) according to Eq. (4):

$V_{d}=1.61\left(\overline{w^{\prime} \rho_{\mathrm{H}_{2} 0^{\prime}}} / \rho_{\mathrm{air}}\right)+(1+1.61 q)\left(\overline{w^{\prime} T^{\prime}} / T\right)$

The Webb correction reached maximum values of 0.05 to $0.15 \mathrm{~cm} \mathrm{~s}^{-1}$ during the middle of each day $(10 \mathrm{a} . \mathrm{m}$. until 3 p.m.) and was negligible (less than $\pm 0.02 \mathrm{~cm} \mathrm{~s}^{-1}$ ) in the mornings and evenings. These corrections are incorporated in the results presented in Figs. 6 and 7. However, the aerosol fluxes depended on moisture variations more through the hygroscopic growth corrections than on WPL corrections. 


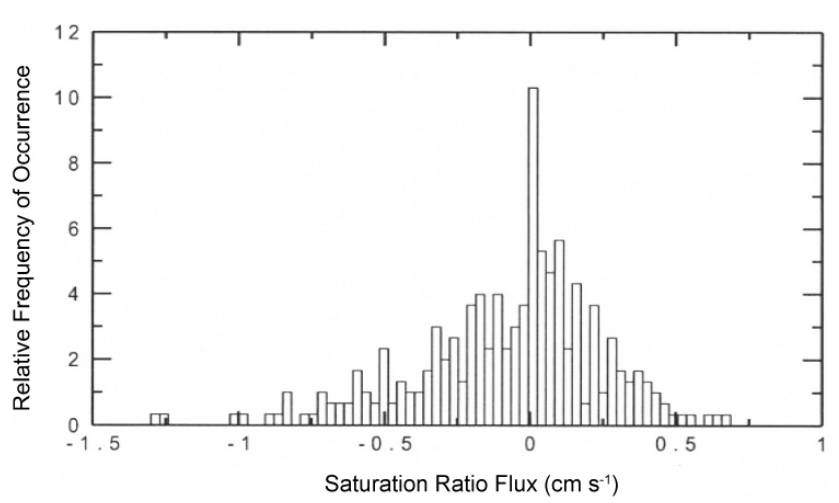

Fig. 5. Frequency of occurrence for saturation ratio fluxes $\left(\overline{\mathrm{w}^{\prime} \mathrm{S}^{\prime}}\right)$ during BEARPEX'07 measurements. The positive values were observed at night or early morning while negative values were observed during the middle of the day. Negative values of $\overline{w^{\prime} S^{\prime}}$ are downward.
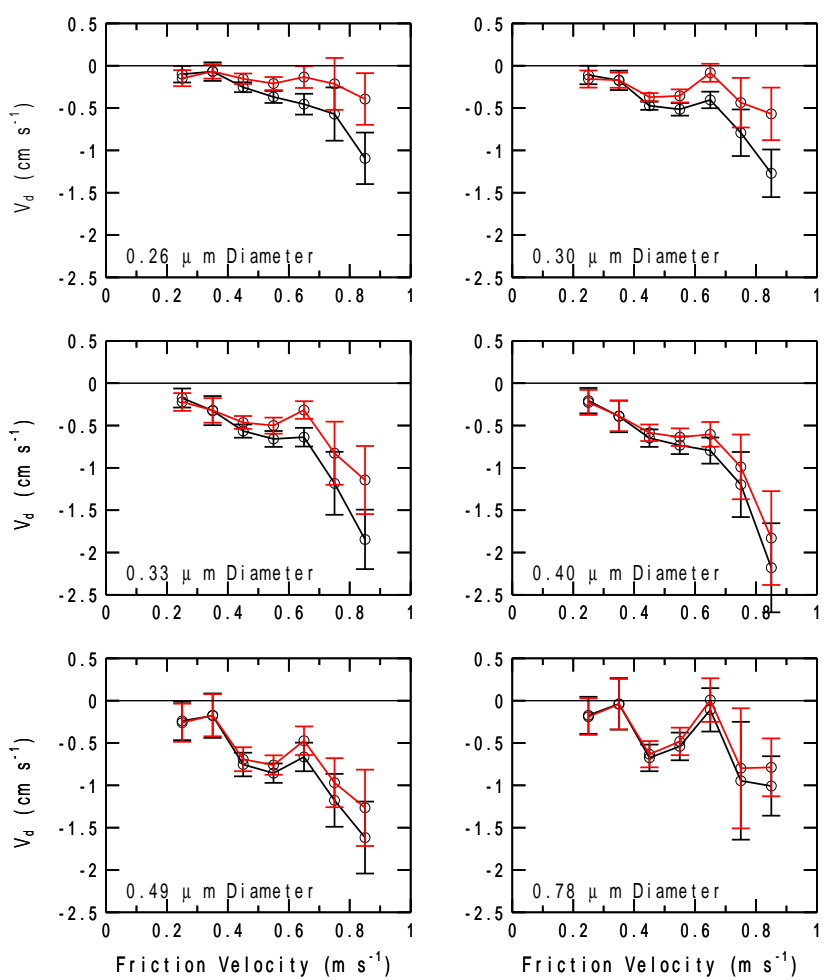

Fig. 6. Aerosol deposition velocities (daytime measured values, WPL corrected) versus friction velocity, both with (red) and without (black) the hygroscopic growth correction. Bars indicate \pm one data standard error (negative $V_{d}$ is downward).

\subsection{Dependence on friction velocity}

Both the transport of accumulation mode particles by turbulence through the atmospheric surface layer and their subsequent removal by inertial impaction ought to depend on friction velocity (Pryor et al., 2008; Gallagher et al., 1997).

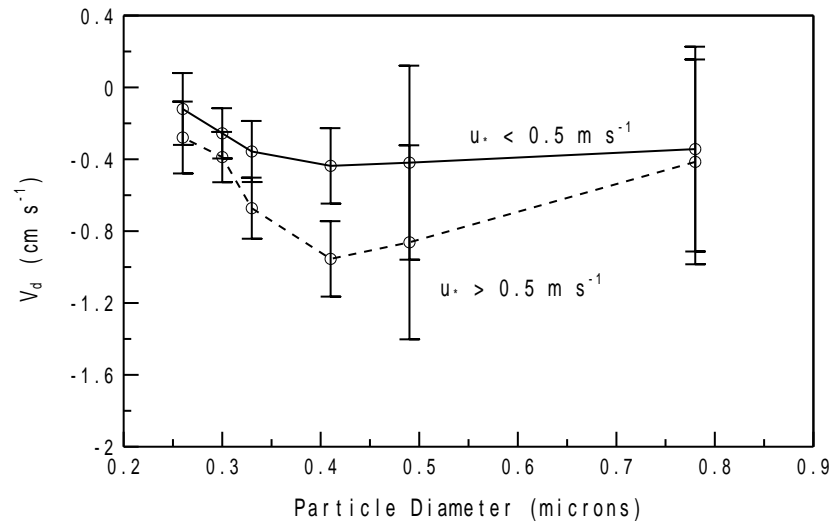

Fig. 7. Size dependence of aerosol deposition velocity (corrected for hygroscopic growth and WPL). Bars indicate \pm the average counting error for single $30 \mathrm{~min}$ fluxes (negative $V_{d}$ is downward).

As shown in Fig. 6, aerosol deposition velocity was larger in magnitude for higher values of friction velocity $\left(u^{*}\right)$, i.e. $V_{d}$ becomes more negative. Negative fluxes and negative $V_{d}$ imply downward transfer here (towards the ground, consistent with the sign of vertical velocity, $w$ ). Table 2 provides the regression relationships between $V_{d}$ and $u^{*}$ for the four particle sizes that have acceptable counting errors.

\subsection{Size-dependence of deposition velocity}

Aerosol turbulent removal during BEARPEX was primarily controlled by processes occurring near the canopy elements (needles here) in that the aerodynamic resistance to particle transfer is much smaller than the sum of resistances from any quasi-laminar surface layer around the needle and for surface uptake. This was examined by determining a "surface deposition velocity" $\left(V_{d s}\right)$ that has the aerodynamic resistance (determined here as: $U / u^{*^{2}}$ ) subtracted from $V_{d}^{-1}$ to produce $V_{d s}$ (Gallagher et al, 1997). It was found that all 30 min BEARPEX data had a result that $V_{d s} \geq 0.93 V_{d}$. Since $V_{d} \approx V_{d s}$, measurements of accumulation mode aerosol $V_{d}$ ought to display a diameter dependence that depends primarily on impaction and interception processes that occur near the needle surface (Pryor et al., 2008; Gallagher et al, 1997).

Particle inertial impaction ought to depend on aerosol diameter because larger accumulation mode particles that move at the fluid velocity (as assumed in EC) have more momentum than smaller particles in the same fluid parcel for a constant particle density. Thus, the removal of accumulation mode particles onto a forest canopy and the magnitude of the resulting $V_{d}$ ought to increase with both $u^{*}$ (the velocity scale for particles approaching the needles) and $D_{p}$. Figure 7 shows that the magnitude of aerosol $V_{d}$ (negative is downward) during BEARPEX did increase with particle size for the smaller accumulation mode aerosol $\left(0.25 \leq D_{p} \leq 0.44 \mu \mathrm{m}\right)$ 

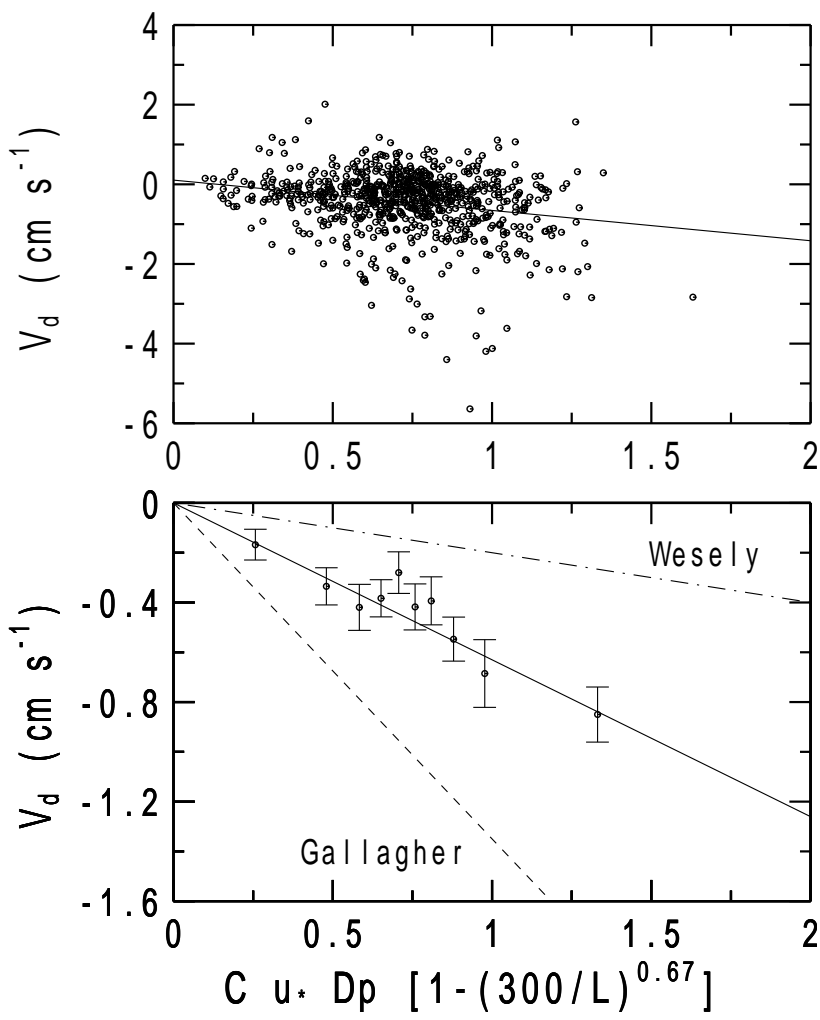

Fig. 8. Parameterization of aerosol deposition velocity $\left(V_{d}\right)$. The points represent the relationship between parameterized $V_{d}$ (X axiscalculated from Eq. 5) and measured $V_{d}$ (Y axis) from BEARPEX. The upper panel compares $30 \mathrm{~min}$ values while the bottom panel compares bin averaged values. The lines in the bottom panel represent different coefficients $(c)$ in the parameterization described by Eq. (5): the solid line has $c=0.63$ as the best fit to BEARPEX 2007 $V_{d}$ observations; the dash line has $c=1.35$ from Gallagher's $V_{d}$ data over forest; and the dot/dash line has $c=0.2$ from Wesely's $V_{d}$ data that were collected over grass (bars describe \pm one data standard error).

during both low and high friction velocity time periods; in this figure the plotted errors bars represent the average counting error at that $D_{p}$ for a single $30 \mathrm{~min}$ flux. The apparent decrease in the magnitude of the measured values of $V_{d}$ for $D_{p} \geq 0.5 \mu \mathrm{m}$ is considered less reliable due to the larger counting uncertainties.

Figure 8 presents a comparison of BEARPEX values for $V_{d}$ for the four smaller diameters (i.e., the smallest counting uncertainties) with those that are predicted by a parameterization that includes $D_{p}, u^{*}$, and Obukov length $(L)$ for both individual 30-min. particle fluxes (top panel) and for mean values (for data binned into ten equal increments of the RHS of eq.5; bottom panel). Gallagher et al. (1997) and Wesely et al., (1985) previously fit this parameterization to their measured aerosol $V_{d}$ for unstable to neutral conditions. While the numerical coefficient $(C)$ in Eq. (5) for BEARPEX daytime data was 0.63 (below), Gallagher's data for forest produced a coefficient that was larger (1.35) whereas Wesely's was smaller $(0.2)$ for his measurements performed over grass.

$V_{d}=C\left(U^{*}\right) D_{p}\left[1+(-300 / L)^{2 / 3}\right]$

where: $V_{d}$ has units of $\mathrm{cm} \mathrm{s}^{-1}, U^{*}$ has units of $\mathrm{m} \mathrm{s}^{-1}$, L has units of $\mathrm{m}$., and $D_{p}$ has units of $\mu \mathrm{m}$.

Figure 8 indicates that this parameterization for $V_{d}$ is most useful for "binned" data (bottom panel where the solid line describes $86 \%$ of the variance in the plotted points) which can be presumed to average out run-to-run 30-min. variation (top panel) that is common to observed EC fluxes. BEARPEX $V_{d}$ results fall between those for Wesely (grass) and Gallagher (forest) and are about $1 / 2$ of values predicted from eq.5 using Gallagher's coefficient of 1.35 .

\section{Discussion}

When the low daytime RH were first observed at the Blodgett Forest site, it was expected that the hygroscopic growth correction might be small due to the combination of low daytime $\mathrm{RH}$ and the expected hygrophobic nature of aerosol composition in the area (Carrico et al., 2005). For the BEARPEX 2007 data, the steepness of the Junge slope of the number-size distribution offset the effect of small hygroscopic growth. The saturation ratio flux $\overline{\mathrm{w}^{\prime} \mathrm{S}^{\prime}}$ during BEARPEX was similar to values reported for EFLAT (Vong et al., 2004) and HAPEX (Kowalski, 2001). Saturation ratio flux determined the sign of this hygroscopic growth correction but the slope of the aerosol size distribution and the hygroscopic growth parameter generally controlled its magnitude. It is likely that larger vertical velocity fluctuations over the "rougher" Blodgett Forest canopy compared to short grass in EFLAT resulted in better moisture vertical transport for a given RH gradient. Although the hygroscopic growth correction was moderate compared to the earlier EFLAT experiment in Oregon, it was important to the precise determination of aerosol deposition velocity at any diameter during BEARPEX.

There were too few stable cases sampled with good fetch during BEARPEX 2007 to fully characterize the relationship of aerosol $V_{d}$ to atmospheric stability beyond the unstable to neutral conditions that apply to Eq. (5). $V_{d}$ had its largest magnitude during windy (high $u^{*}$ ) afternoon conditions.

It is noteworthy that the FAST instrument captured considerable particle flux at some higher frequencies that appear to be almost "white noise" in the top panel of Fig. 2. This strongly suggests that examination of spectra alone is not sufficient to diagnose high frequency flux loss.

The apparent decrease in magnitude of aerosol $V_{d}$ for $D_{p}>0.44 \mu \mathrm{m}$ during BEARPEX likely reflects the fact that these fluxes are especially noisy due to higher counting errors. We consider that the size dependence of $V_{d}$ for $D_{p} \leq 0.44 \mu \mathrm{m}$ is correctly characterized here but that values for the larger particles are more uncertain. 
These BEARPEX results for particle $V_{d}$ are smaller by a factor of about 2 (Fig. 8) than those from studies that were conducted over forest by Gallagher et al. (1997) in terms of the dependence of deposition velocity on friction velocity $\left(u^{*}\right), D_{p}$, and L ; both are larger than values predicted from the original Slinn (1982) model. Differences between BEARPEX and Gallagher's $V_{d}$ results (and the coefficients in eq.5) are partly attributable to the loss of flux at high frequencies $(\geq 6-9 \%)$ during BEARPEX but also could relate to different data pre-processing and screening choices (e.g., BEARPEX data were corrected for hygroscopic growth but Gallagher neglected this correction because that probe measured "dry" $D_{p}$ ). It is encouraging that the form of parameterization used by Gallagher et al. and Wesely et al. (1985) captures much of the dependence of BEARPEX deposition velocities on particle size, friction velocity, and stability and produce similar magnitudes of the flux. These factor of 2 differences between BEARPEX and Gallagher et al. (1997) values for accumulation mode aerosol $V_{d}$ are smaller than textbook cited "uncertainties of at least an order of magnitude" (Seinfeld and Pandis, 1998).

\section{Conclusions}

Aerosol deposition velocity $\left(V_{d}\right)$ varied from -0.2 to $-1.0 \mathrm{~cm} \mathrm{~s}^{-1}$ during daytime as a function of both diameter and friction velocity $\left(u^{*}\right)$ for particle diameters from $0.25 \mu \mathrm{m}$ to $0.44 \mu \mathrm{m}$. Uncertainties associated with particle counting were evaluated from the data and found to be substantial for $0.44 \mu \mathrm{m}<D_{p} \leq 1 \mu \mathrm{m}$. A hygroscopic growth correction to $V_{d}$ was necessary for accurate results despite the low RH and relatively hygrophobic nature of the particles. A comparison of the cospectra for particles with those for heat and water vapor suggests that the measured aerosol fluxes were underestimated by a minimum of $6-9 \%$ at the higher frequencies and these underestimates may be larger. The BEARPEX 2007 daytime values of aerosol deposition velocity for $D_{p}<0.5 \mu \mathrm{m}$ are relatively well described for unstable to neutral conditions by a parameterization that is based on $D_{p}, U^{*}$, and $1 / L$.

Acknowledgements. This research was supported by the National Science Foundation Atmospheric Chemistry Program under grant ATM-0729944. We thank Allen Goldstein, Ron Cohen, and their staff for support during BEARPEX and Sierra Pacific for the use of their property. We gratefully acknowledge our OSU colleagues Jay Simpkins, for hardware design and machining, and Christoph Thomas for useful discussions about the data.

Edited by: A. B. Guenther

\section{References}

Baron, P. and Willeke, K.: Aerosol Measurement: Principles, Techniques, and Applications, Wiley-InterScience, 2005.

Carrico, C. M., Kreidenweis, S. M., Malm, W. C., Day, D. E. Lee, T., Carrillo, J., McMeeking, G. R., and Collett, J. L.: Hygroscopic growth behavior of a carbon-dominated aerosol in Yosemite National Park, Atmos. Environ. 39, 1393-1404, 2005.

Charlson, R. J., Schwartz, S. E., Hales, J. M., Cess, R. D., Coakley, J. A., Hansen, J. E., and Hofmann, D. J.: Climate forcing by anthropogeic aerosols, Science, 255, 423-430, 1992.

Charlson, R. J., Lovelock, J. E., Andreae, M. O., and Warren, S. G.: Oceanic phytoplanton, atmospheric sulfur, cloud albedo, and climate, Nature, 326, 655-661, 1987.

Erisman, J. W., Draaijers, G., Duyzer, J., Hofschreuder, P., VanLeeuwen, N., et al.: Particle deposition to forests-summary of results and application, Atmos. Environ. 31, 321-332, 1997.

Eugster, W. and Senn, W.: A cospectral correction for measurement of turbulent $\mathrm{NO}_{2}$ flux, Bound.-Lay. Meteorol., 74, 321340, 1995.

Fairall, C. W.: Interpretation of eddy correlation measurements of particulate dry deposition, Atmos. Environ., 18, 3129-3137, 1984.

Foken, T., Gockede, M., Mauder, M., Mahrt, L., Amiro, B., and Munger, W.: Post-field data quality control, in: Handbook of Micrometeorology edited by: Lee, X., Massman, W., and Law, B., Kluwer Academic Press, Dordrecht, The Netherlands, 181208, 2004.

Gallagher, M. W., Beswick, K. M., Duyzer, J., Westrate, H., Choularton, T. W., and Hullmmelshoj, P.: Measurements of aerosol fluxes to Speulder Forest using a micrometeorological technique, Atmos. Environ. 31, 359-373, 1997.

Goldstein, A. H., Hultman, N. E., Fracheboud, J. M., Bauer, M. R., Panek, J. A., Xu, M., Qi, Y., Guenther, A. B., and Baugh, W.: Effects of climate variability on the carbon dioxide, water, and sensible heat fluxes above a ponderosa pine plantation in the Sierra Nevada (CA), Agric. Forest Meteorol. 101, 113-129, 2000.

Hegg, D. A., Covert, D. S., and Jonsson, H. H.: Measurements of size-resolved hygroscopicity in the California coastal zone, Atmos. Chem. Phys., 8, 7193-7203, doi:10.5194/acp-8-7193-2008, 2008.

Hegg, D. A., Covert, D. S., Jonsson, H., and Covert, P. A.: An instrument for measuring size-resolved hygroscopicity at both sub- and super-micron sizes. Aerosol Sci. Technol. 41, 873-883, 2007.

Hegg, D. A., Covert, D. S., Crahan, K. K., Jonsson, H. H., and Liu,Y.: Measurements of the Aerosol Size-Resolved Hygroscopicity at Sub and Supermicron Sizes. Geophys. Res. Lett. 33, L21808, doi:10.1029/2006GL026747, 2006.

Hicks, B. B., Draxler, R. R., Albritton, D. L., Fehsenfeld, F. C., Dodge, M. C., Schwartz, S. E., Tanner, R. L., Hales, J. M., Meyers, T. P., and Vong, R. J.: Atmospheric Processes Research and Process Model Development, State-of-Science /Technology Report Number 2, National Acidic Precipitation Assessment Program (NAPAP), Washington DC, USA, 1991.

Howell, J. F. and Mahrt, L.: Multi-resolution flux decomposition, Bound.-Lay. Meteorol., 83, 117-137, 1997.

Junge, C. E.: Air chemistry and radioactivity, International Geophysics Series, Academic Press, New York, USA, 4, 113-123, 1963. 
Kasten, F.: Visibility forecast in the phase of pre-condensation, Tellus, 21, 631-635, 1969.

Kowalski, A. S.: Deliquescence induces eddy covariance and estimable dry deposition errors, Atmos Environ., 35, 4843-4851, 2001.

Kowalski, A. S., Anthoni, P. A., Vong, R. J., Delany, A. S., and Maclean, G.: Deployment and evaluation of a system for ground-based measurement of cloud liquid water fluxes, J. Atmos. Ocean. Tech., 14, 468-479, 1997.

Lee, X., Finnigan, J., and Paw U, K. T.: Coordinate systems and flux bias error, in: Handbook of Micrometeorology, edited by: Lee, X., Massman, W., and Law, B., Kluwer Academic Press, Dordrecht, The Netherlands, 33-66, 2004.

Massling, A., Stock, M., and Wiedensohler, A.: Diurnal, weekly, and seasonal variation of hygroscopic properties of submicrometer urban aerosol particles, Atmos. Environ., 39, 3911-3922, 2005.

Moore, C. J.: Frequency response corrections for eddy correlation systems, Boundary Layer Meteorol. 37, 17-35, 1986.

Nemitz, E., Gallagher, M. W., Duyzer, J. H., and Fowler, D.: Micrometeorological measurements of particle deposition velocities to moorland vegetation, Q. J. Roy. Meteorol. Soc. 128, 22812300, 2002.

Pryor, S. Gallagher, M. W., Sievering, H., Larsen, S. E., Barthemie, R. J., Birsan, F., Nemtiz, E., Rinne, J., Kulmala, M., Gronholm, T., Taipale, R., and Vesala, T.: A review of measurement and modeling results of particle atmosphere-surface exchange, Tellus 60B, 42-75, 2008.
Seinfeld, J. H. and Pandis, S. N.: Atmospheric chemistry and physics: from air pollution to climate change, Wiley and Sons, New York, USA, 969-971, 1998.

Slinn, W. G. N.: Predictions for particle deposition to vegetative canopies, Atmos. Environ., 16, 1785-1794, 1982.

Vickers, D. and Mahrt, L.: Quality control and flux sampling problems for tower and aircraft data, J. Atmos. Ocean. Technol., 14, 512-526, 1997.

Vickers, D. and Mahrt, L.: The cospectral gap and turbulent flux calculations, J. Atmos. Ocean. Technol., 20, 660-672, 2003.

Vong, R. J., Vickers, D., and Covert, D. S.: Eddy correlation measurements of aerosol deposition to grass, Tellus 56B, 105-117, 2004.

Webb, E. K., Pearman, G. I., and Leuning, R.: Correction of flux measurements for density effects due to heat and vapor transfer, Q. J. Roy. Meteor. Soc., 106, 85-100, 1980.

Wesely, M. L., Cook, D. R., Hart, R. L., and Speer, R. E.: Measurements and parameterization of particulate sulfur dry deposition over grass, J.Geophys. Res., 90, 2131-2143, 1985. 